\title{
Service Orientation in Demand-Supply Chains: Towards an Integrated Framework
}

\author{
Mohammad R. Rasouli, Rob J. Kusters, Jos J.M. Trienekens, and Paul W.P.J. Grefen \\ School of Industrial Engineering at Eindhoven University of Technology, \\ P.O. box: 513, 5600 MB Eindhoven, The Netherlands \\ \{M.Rasouli, J.J.M.Trienekens, P.W.P.J.Grefen\} @tue.nl, \\ Rob.Kusters@ou.n1
}

\begin{abstract}
Offering customer-centric value through dynamic and networked capabilities is a strategic need in the current business environment. This strategic need can be met by a Service-Oriented Demand-Supply Chain (SODSC) concept. Various direct and indirect notions in different contexts have been developed about SODSC concept. However, the lack of integration between these notions can easily lead to confusion. This paper aims to counter this confusion by providing a framework for structuring various related notions and explaining them through illustrative cases. Based on a cybernetic system approach, the serviceoriented value, partnership and control aspects of SODSC have been investigated respectively. On the basis of a distinction between demand and supply chain perspectives, two distinct dimensions of service orientation have been explored in each of the aspects. The resulting integrated framework, visualized by three related two-dimensional matrices and illustrated by real cases, offers the possibility to characterize and analyze the various SODSC notions.
\end{abstract}

Keywords: service orientation, partnership, control, demand-supply chain, framework.

\section{Introduction}

The current business environment is characterized by empowered customers and globally networked suppliers. In this environment, the offering of customer-centric value through dynamic capabilities is a strategic issue. This strategic issue has led to the development of new dominant logics, especially in the marketing and operations management contexts [1]. Service-Dominant (S-D) logic as a new paradigm that emphasizes customer-centric value creation has changed the conventional marketing nature from transactional to relational [2]. Also the necessity to provide integrated and life-cycle based product services combinations, rather than single products or services, has transformed the traditional stable supply chains to adaptive supply networks [3]. This means that service orientation in demand and supply chains can be conceived as an essential requirement to survive in the current business environment.

The importance of service orientation in the demand and supply chains has led to the development of various related notions such as S-D logic [1, 2, 4] Product Service 
System (PSS) [5], Industrial Product Service System $\left(\right.$ IPS $\left.^{2}\right)[6]$, service enhanced products [7] and solution management [8]. Although this variety of views and notions helps to understand the different aspects of service orientation, the lack of integration between them can easily lead to confusion. To deal with this confusion, in this paper we apply the Service-Oriented Demand-Supply Chain concept that is reflected by SODSC. This concept addresses the differences between the responsibility of demand chain and supply chain activities for service orientation [9]. It reflects the necessity of integration of these activities as well. Based on the SODSC we aim to develop an integrated framework that enables to bring together different related notions.

In this paper, to deal with the complexity and confusion of diverse notions related to SODSC, we distinguish between different aspects and different perspectives (i.e. demand chain and supply chain) of SODSC. The different aspects will be explored separately through a cybernetic system based representation of SODSC. This representation of SODSC includes respectively the service-oriented value, the partnership, and the control of SODSC. This kind of logical reduction of complexity helps to position different service-oriented notions in literature in the integrated framework. The resulting integrated framework, visualized by three related twodimensional matrices, is illustrated by three real cases. The proposed integrated framework along with the illustrative cases enables recognition of different conceivable service orientation transitions. This integrated framework also enables the analysis of the characteristics of a particular organization and its demand-supply chain from the service orientation point of view.

In the next section, the cybernetic system based representation of SODSC is introduced. The distinct aspects of SODSC result from this representation. Also the distinction between supply and demand chain perspectives is illustrated. These aspects and perspectives shape the basis for an investigation and positioning of different service-oriented notions. Subsequently, the three main aspects of SODSC, i.e. service oriented value, partnership and control, are investigated separately in the third, fourth and fifth section. The sixth section provides a discussion on the results of the investigation. The final section concludes the paper and proposes the future research steps to be made.

\section{The Approach for Structuring and Explaining SODSC}

As stated before, we will apply cybernetic based system theory to investigate different aspects of SODSC. System theory is based on the idea that basic principles are common to all systems, independent of the area of science to which they belong [10]. Regarding the multi-disciplinary nature of service orientation [11], these basic principles of system theory, enable development of an integrated view on the different aspects of service orientation. System theory also provides a terminological setting that is useful to overcome misunderstandings related to the usage of different terms in different contexts.

A system is defined as "a set of interacting or interdependent components forming an integrated whole" [12]. System approaches can be characterized based on the level of complexity [4], but can also be classified as physical, mathematical and cybernetic models, according to the similarity and the degree of abstraction [5]. In comparison 
with other system approaches, the cybernetic approach is suggested to be used in complex contexts [4]. So with respect to the complex nature of SODSC [13], this approach of system thinking provides proper possibilities to deal with complexity.

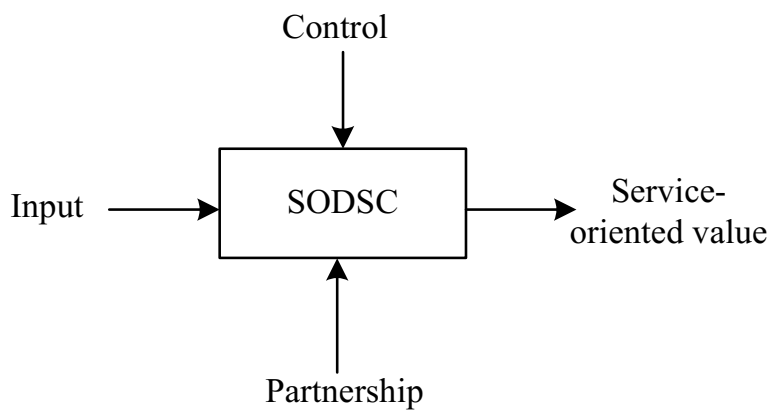

Fig. 1. The cybernetic system based representation of SODSC aspects

To encounter the complexity and confusion in SODSC, a cybernetic system approach reduces the SODSC to its logical aspects. In line with previous research that has developed system based representations of supply or demand chains [14, 15], we distinguish different aspects of SODSC, see Fig. 1. SODSC can be considered as a system that provides a specific type of output for customers (what) through supportive mechanisms (how) under a certain type of control (why). The clarification of these mentioned aspects leads to a better understanding of SODSC. So, firstly the serviceoriented value is investigated as the output aspect of SODSC. The clarification of different dimensions of service-oriented value, as a core concept in SODSC, facilitates the exploration of service orientation in the other aspects. Secondly, the impact of service orientation on the supportive mechanism aspect in demand-supply chain is investigated. Taking into account the networked nature of SODSC, partnership is explored as the key supportive mechanism aspect. Finally, the characteristics of the control aspect in the SODSC are examined. Since in the networked business environment the main focus is on the strategic alliance/partnership [16], the most important input in our model are the partners that are going to participate in a networked business. So taking into account the partnership as the main supportive mechanism in our model, we don't have to investigate the input aspect separately.

Besides the cybernetic system based reduction of complexity, we also distinguish between demand chain and supply chain perspectives on service orientation. Based on the value chain framework [17], the demand chain perspective focuses on the marketing, sales and customer relationship management activities. The supply chain perspective focuses on inbound logistics, operations and outbound logistics activities. The demand chain perspective responds to the necessity for understanding, creating and simulating customer demand [9] and can be recognized as the value creation or the value obtainment system. On the other hand, the supply chain perspective includes all the supply processes to fulfill the customer demand [9] and can be called the value delivery system.

By using of foregoing distinctions, we will characterize different service-oriented notions in the three main aspects, respectively: service-oriented value, service-oriented 
partnership and service-oriented control. In each aspect, in accordance with the distinction between demand and supply chain perspectives, two dimensions of serviceorientation are considered as well, i.e. value obtainment and value delivery. Consequently three two dimensional matrices will be developed in the next sections to investigate the various SODSC notions.

To explain further the characteristics of SODSC notions through the proposed matrices, three real-life illustrative cases will be described. For this purpose, we have chosen three cases of service orientation in the ICT industry. The first case is about Microsoft that has experienced a noteworthy shift from being a supplier of software for IBM personal computers, to a provider of customer-centric products and services through its huge service ecosystem [18]. The second illustrative case of service orientation is the IBM Rational solution for Collaborative Lifecycle Management (CLM) [19]. The CLM is an extensible platform that helps to integrate different related products and services across the software life cycle. The last case is about Accenture's cloud platform that offers integrated hybrid IT solutions [20]. This platform is founded on the integration between different products and services that are provided through different service ecosystems. Each of the mentioned cases describes a different type of service orientation transition that will be discussed based on the proposed framework. This case based illustration can be conceived as the primary step for showing the applicability and generalizability of the proposed framework.

\section{The Service-Oriented Value Aspect of SODSC}

The investigation of SODSC depends on a clear understanding of the service-oriented value. Different notions in marketing, operations management and information management contexts have led to confusion about the service oriented value. In our approach, we distinguish between these notions based on the supply chain and demand chain perspectives. On the basis of these two perspectives, two different dimensions of service-oriented value can be recognized in literature as well [21]. The first dimension of service-oriented value, i.e. from a demand chain perspective, is established on the basis of customer interaction to create value. The second dimension of service-oriented value, i.e. from a supply chain perspective, is established on extending capabilities of a supply chain to cover the broader requirements of customers through adding new services to the core products of a supply chain.

The first dimension of service oriented value focuses on the interactions between suppliers and customers rather than the ability of a supply chain to provide an extended range of products and services, see Fig. 2, vertical axis. Within this dimension, the emphasis is on the customer centric interactions that shape the value. Within this dimension, the service orientation is reflected by the customer centric definition of the value. This dimension emphasizes the more prominent role of a customer for obtaining the value. It suggests that value is always determined by the customer as value-in-use, whether in direct interaction with the supplier or in indirect interaction through goods in use. Within this dimension of service orientation, value lies not in building more features into products and services such as mentioned in the integrated product services, but in providing more and varied opportunities to consumers for co-creating personalized experiences [22]. 


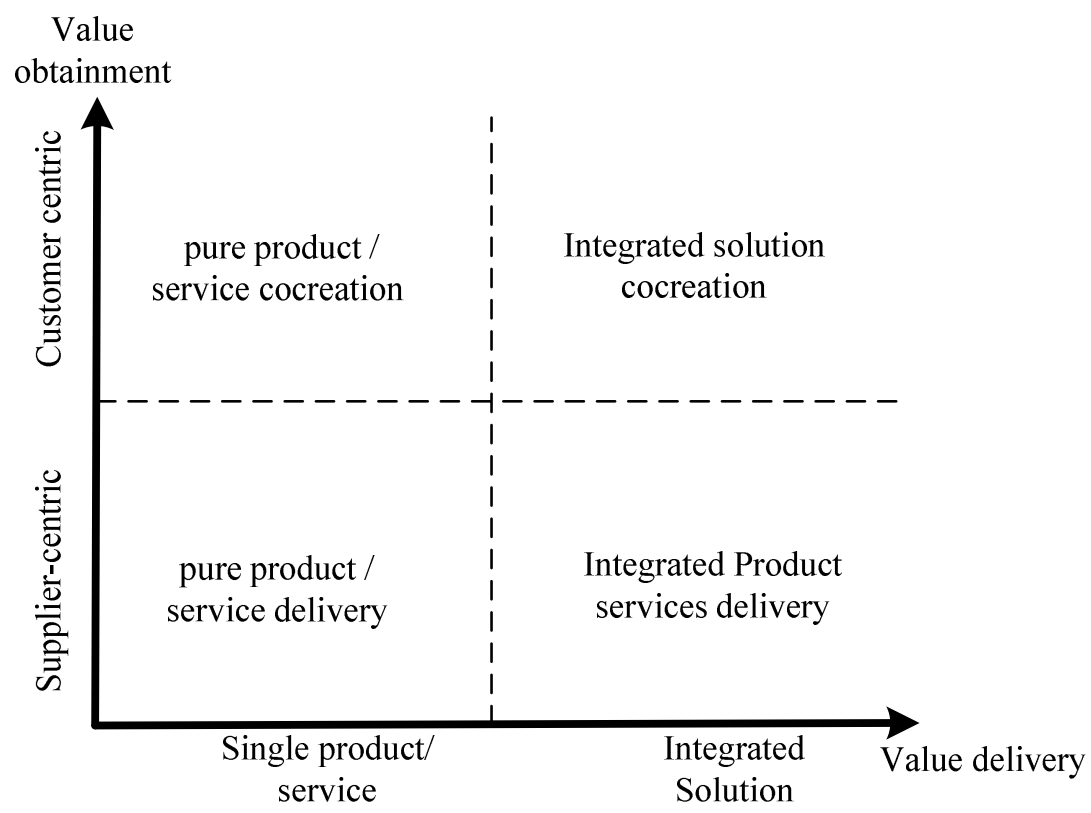

Fig. 2. The characterization of service-oriented value

The second dimension, i.e. the supply chain perspective on service orientation, predicates the ability of a supply chain to deliver new services in addition to the core offerings of a supply chain, see Fig. 2, horizontal axis. This type of service orientation is a supply chain transition from delivering pure products or services to delivering integrated product services packages. This transition is inevitable for companies in mature industries due to the need for higher customer value. Two most important strategic directions that lead supply chains towards the offering of integrated product services can be described as respectively:

1- Time based extension of provider responsibility: from product/service delivery towards product lifecycle management (PLM);

2- Risk based extension of provider responsibility: from output oriented towards result oriented responsibility;

Both mentioned dimensions of service orientation, can be considered as customer orientation approaches. However, the first dimension responds to customer orientation through value obtainment activities, whilst the second dimension realizes it through value delivery tasks. The combination of both dimensions leads to offer integrated solutions for customers [23]. It means that offering integrated solutions requires customer-centric interactions as well as the ability of providing integrated product services.

The characterization of the service-oriented value, see Fig. 2, can be illustrated by the cases introduced in section 2. Microsoft's evolution from being a supplier of software for IBM personal computers to co-creating through independent developers, who interact with end users, can be considered as service orientation from a demandchain perspective (i.e. the value obtainment dimension). The IBM's CLM product that 
supports the entire software development lifecycle from requirement to deployment through integrated and collaborative tooling can be seen as the service orientation in supply perspective (i.e. the value delivery dimension). Also the Accenture cloud platform, that supports hybrid IT solution cocreation through customer interaction with different ecosystems, is an illustrative case for integrated solution cocreation (i.e. the ultimate combination of value obtainment and value delivery dimensions). These illustrative cases show that the proposed distinction between the two dimensions of service-oriented value enables the characterization and the interpretation of serviceorientation in real-life business situations.

\section{The Partnership Aspect of SODSC}

The partnership aspect in our cybernetic approach to SODSC, see Fig. 1, describes the alliance of stakeholders to provide service-oriented value. In line with the two distinct dimensions of service-oriented value, i.e. from the demand and the supply chain perspectives, two different dimensions for service orientation of the partnership aspect of SODSC can be recognized. The customer-supplier relationship dimension, established from a demand chain perspective, underlines the role of a customer as an active actor in partnership models that support the customer interaction for value cocreation. The supplier-supplier relationship dimension, established from a supply chain perspective, emphasizes the suppliers' own relationship to aid delivery of integrated product services. These two different dimensions for the characterization of the partnership in SODSC are shown in Fig.3.

The customer-supplier relationship dimension, see Fig.3, due to its marketing origination, emphasizes the costumer involvement in value creation rather than the partnership between suppliers [24]. This dimension is in line with the customer empowerment trend in the marketing context. Customers can engage in dialog with suppliers during each stage of product design and product delivery. This form of dialog should be seen as an interactive process of learning together [25]. Customers as active actors to co-create value can take different roles such as co-designer, innovator, marketer and socially responsible actor [26]. In this way, the service ecosystem and value network [27] notions have been developed to address new types of partnership. In the service ecosystem, a customer as an active actor coproduces service offerings, exchanges service offerings, and co-creates value [1]. This means that in a value network the supplier-supplier relationship is the subordinate of customer-supplier relationship. In other words, in a value network the customer as a value co-creator determines the suppliers' requirements to respond the customized value.

On the other hand, the supplier-supplier relationship dimension, see Fig. 3, takes into consideration the partnership characteristics that enhance transition from pure products or services towards integrated product services. Delivering result-oriented product services that supports the availability of the delivered value in its whole life cycle requires a strong collaboration between suppliers. Also delivering integrated product services, which is customer oriented in its nature, requires more market sensitiveness in the supplier-supplier relationship. This collaboration between suppliers that can be adopted based on the customer needs to deliver customized integrated product services can be characterized as an adaptive/agile supply network [28, 29]. 
With respect to the characterization of service-oriented value (Fig.2), partnership mechanisms to support the cocreation of integrated solutions might be characterized by both customer-centric as well as adaptive. This is reflected by the combination of two dimensions of service-oriented partnership in Fig.3. This type of partnership supports a flexible and dynamic collaboration to respond to the emerging opportunities originated from customer involvement in value creation. The dynamic and opportunity based partnership to deliver the cocreated integrated solution, can be handled through a collaborative value network, see Fig. 3.

In line with the foregoing section, and for a further clarification of the two dimensions of service orientation based on the partnership aspect, we again address the three cases introduced in section 2. Microsoft Partner Ecosystem that supports the co-creation of customer-centric products and services around the Microsoft technologies can be considered as an illustrative case of a value network (i.e. the customer-supplier relationship dimension in Fig.3). In this ecosystem that consists of 640,000 partners, members interact with customers independently to provide customer-centric value [18].The CLM of IBM can be delivered as a whole package or fragmented parts of the integrated package based on the customer requirements. So the relationship between the suppliers of the different elements of CLM should be adaptive (i.e. the supplier-supplier relationship dimension in Fig.3). The Accenture cloud platform for the co-creation of integrated solutions might be able to coordinate between suppliers in different value networks. It means that the partnership aspect in support of the Accenture cloud platform consists of the different value networks as well as the adaptive relationship between the suppliers who are members of different value networks (i.e. the combination of the two dimensions of service-oriented partnership in Fig 3). These three cases indicate that organizations pursuing a particular direction for providing service-oriented value require a particular type of partnership characteristics.

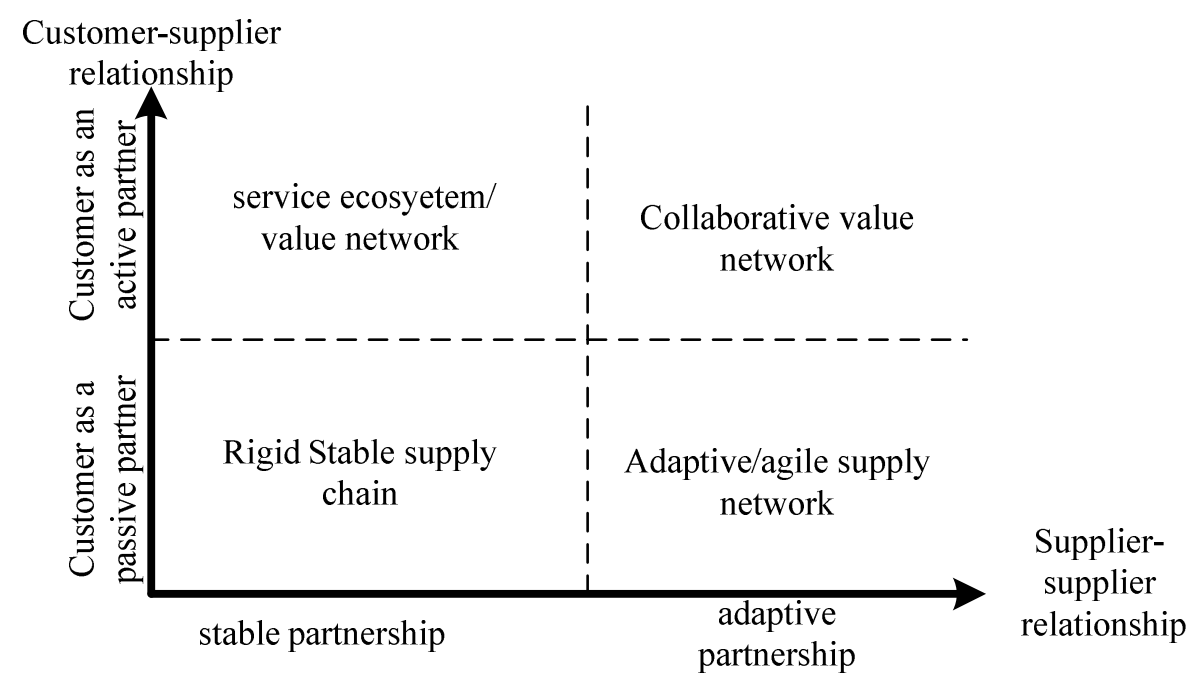

Fig. 3. The characterization of the partnership aspect of SODSC 


\section{The Control Aspect of SODSC}

Following the distinction between service orientation in demand and supply chain perspectives, two different dimensions can be addressed of the control aspect as well. These two dimensions are presented in Fig.4. Where from a demand chain perspective, the control focuses on the handling of customer-supplier relationship, from a supply chain perspective the control focuses on the coordination between suppliers. The main priority of the first perspective is to lead the system towards a better obtainment of customer satisfaction, where the second perspective emphasizes more efficiency and responsiveness in the delivery process.

The service orientation in the customer-supplier relationship control dimension addresses the shift from a transactional approach for value obtainment towards relational dominant logic (See Fig.4). The transactional approach as a pre-dominant logic for value obtainment is product-oriented and can be seen as trying to get the customer fitted to the product. The transactional approach for the value obtainment focuses on customer attraction, e.g. through controlling '4Ps' (Price, Product, Promotion and Placement) as the most important variables for the value obtainment [30]. However, the relational value obtainment proposes a different approach that is customer-centric rather than product-oriented. The relational value obtainment emphasizes customer experience rather than customer attraction. The customer experience-centric control is based on customers' commitment, trust, satisfaction, communication, and the seller's customer orientation [31].

Customer-supplier

relationship control

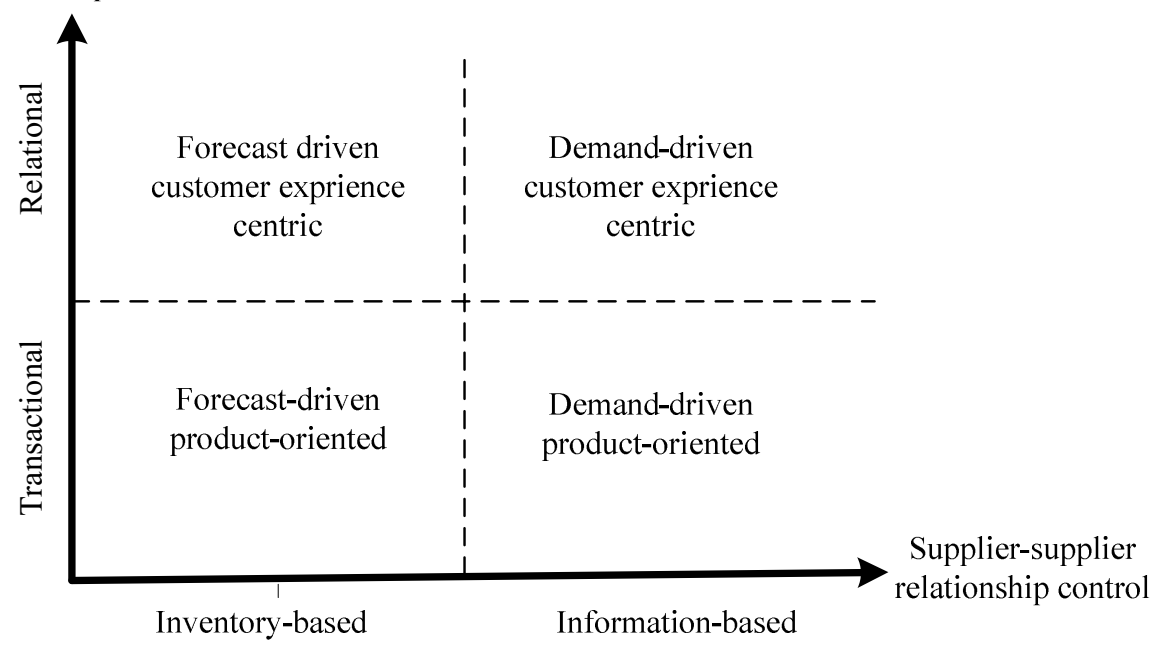

Fig. 4. The characterization of control aspect of SODSC

The second dimension in the control aspect of SODSC describes the coordination between suppliers to provide integrated product services (See Fig.4). According to the corresponding dimension in the service-oriented value and partnership aspects, the 
focus of the control aspect in this dimension should be on the handling of agility and flexibility. Handling the agility requires a market sensitiveness capability in the control aspect to understand and respond to the real demands of customers [29]. This leads the control of the relationship between suppliers from forecast-driven to demand-driven. The demand-driven control, which is based on the real customer demand, requires a real-time access to information. So while the conventional suppliers' relationship control is inventory-based, the service-oriented supply chain control is information-based. This means that the demand-driven control is established on the information that is de-coupled downstream as far as possible. So the real demand information can penetrate into the whole supply chain.

By combining the two mentioned dimensions of service orientation of the control aspect (See Fig.4) it can be concluded that cocreating integrated solutions through a collaborative value network requires control characterized as relational and information-based. In this case, the control aspect of a system is responsible for handling the relationship between the customer and all the potential suppliers in order to obtain the most fitted value, as well as to organize the suppliers to deliver the obtained customized value. In this case control should be able to manage customersupplier interactions through open dialogue and social interactions and also to coordinate the whole supply chain to deliver the obtained customer centric value. This means that control in the collaborative value network should be capable of handling real time integration between value obtainment and value delivery, (See Fig.3). In this case, the dynamics of supplier-supplier relationships originates from the customer experience (that is obtained through customer interaction control).

In accordance with the previous sections, the characterizing control aspect in SODSC can also be recognized in the three cases introduced in section 2 . It can be conceived that the control aspect in the Microsoft ecosystem through an extended and deep relationship with a broad spectrum of customers can obtain customer-centric values for offering new propositions. While, it seems that IBM's CLM should be able to coordinate between different suppliers to handle different and dynamic demands that are requested by customers. Accenture's cloud platform, being able to offer customer-centric integrated solution, should be capable of tracing and obtaining value from different service ecosystems, as well as a dynamic coordination between suppliers to deliver the customer-centric value.

\section{Discussion}

The proposed framework for SODSC contributes towards solving the confusion related to the usage of various notions of SODSC. The distinction between the three different identified aspects of SODSC enables an investigation of a broad range of notions in the literature in a structured way. Also the recognition of two different dimensions in each of the three aspects clarifies the different aims of service orientation in the marketing and manufacturing contexts. S-D logic and "service system" notions, which have emerged as the most important scholarly marketing debates in the last decade, emphasize customer-centric value obtainment. While notions such as IPS ${ }^{2}$, PSS, and service enhanced products, that originated from manufacturing and operations management contexts, address the shift from pure 
product manufacturing towards integrated product services delivery. This type of extreme distinction helps to get a clear understanding of the main focus of the different confusing notions.

The proposed framework can also be used to understand potential transitions of organizations aiming for service orientation. Service oriented organizations, as well as networked businesses, can position them in the proposed framework. Since the three proposed matrices address different aspects of a SODSC, there is a logical dependency between them. Based on this dependency, selection of a particular direction of service orientation at each aspect requires pursuing the same direction in the other aspects. We give three examples to clarify this dependency. First, organizations that based on their strategy are going to focus on customer intimacy as their main service-orientation theme [32], should be able to handle value networks through relational customer experience control, see the left top cell in the matrices proposed in Figure2, Figure 3 and Figure 4. Second, organizations that focus on integrated product services delivery competences should be able to manage agile supply networks through demand-driven control, see the right bottom cell in the matrices proposed in Figure2, Figure3 and Figure 4. Third, innovation based organizations in the service-oriented context, willing to co-create new services to offer integrated solutions for customers, should be capable of managing a collaborative value network through customer-centric and demand-driven control, see the right top cell in the matrices proposed in Figure2, Figure 3 and Figure 4.

\section{Conclusion}

In this paper, through a cybernetic system based representation of SODSC, the three main aspects of SODSC have been investigated, i.e. the service-oriented value aspect, the partnership aspect and the control aspect. This investigation has resulted in three two-dimensional matrices which form together an integrated framework to address the different SODSC notions and views in a structured way. This integrated framework enables to recognize different types of 'real-life' service orientation transitions. The paper also addresses the first steps towards a validation of the integrated framework, i.e. by illustrating and explaining service orientation transitions of three 'real-life' cases in the ICT industry.

Although the proposed integrated SODSC framework is based on literature research, analysis and logical reasoning, and the positioning of the real-life cases shows its usability, more case study research is recommended to validate, strengthen and enrich the framework.

\section{References}

1. Lusch, R.F.: Reframing Supply Chain Management: A Service Dominant Logic Perspective. Journal of Supply Chain Management 47, 14-18 (2011)

2. Vargo, S.L., Lusch, R.F.: Evolving to a new dominant logic for marketing. Journal of Marketing 68, 1-17 (2004) 
3. Gebauer, H., Paiola, M., Saccani, N.: Characterizing service networks for moving from products to solutions. Industrial Marketing Management 42, 31-46 (2013)

4. Maglio, P.P., Spohrer, J.: Fundamentals of service science. Journal of the Academy of Marketing Science 36, 18-20 (2008)

5. Tukker, A., Tischner, U.: Product-services as a research field: past, present and future. Reflections from a decade of research. Journal of Cleaner Production 14, 1552-1556 (2006)

6. Meier, H., Völker, O., Funke, B.: Industrial product-service systems (IPS2). The International Journal of Advanced Manufacturing Technology 52, 1175-1191 (2011)

7. Camarinha-Matos, L.M., Afsarmanesh, H., Koelmel, B.: Collaborative networks in support of service-enhanced products. In: Camarinha-Matos, L.M., Pereira-Klen, A., Afsarmanesh, H. (eds.) PRO-VE 2011. IFIP AICT, vol. 362, pp. 95-104. Springer, Heidelberg (2011)

8. Storbacka, K.: A solution business model: Capabilities and management practices for integrated solutions. Industrial Marketing Management 40, 699-711 (2011)

9. Hilletofth, P.: Demand-supply chain management: industrial survival recipe for new decade. Industrial Management \& Data Systems 111, 184-211 (2011)

10. Von Bertalanffy, L.: General system theory; a new approach to unity of science. 1. Problems of general system theory. Human Biology 23, 302-312 (1951)

11. Bardhan, I.R., Demirkan, H., Kannan, P., Kauffman, R.J., Sougstad, R.: An interdisciplinary perspective on IT services management and service science. Journal of Management Information Systems 26, 13-64 (2010)

12. Backlund, A.: The definition of system. Kybernetes 29, 444-451 (2000)

13. Badinelli, R., Barile, S., Ng, I., Polese, F., Saviano, M., Di Nauta, P.: Viable service systems and decision making in service management. Journal of Service Management 23, 498-526 (2012)

14. Verdouw, C., Beulens, A., Trienekens, J., Van der Vorst, J.: A framework for modelling business processes in demand-driven supply chains. Production Planning and Control 22, 365-388 (2011)

15. Grefen, P.W., Dijkman, R.M.: Hybrid control of supply chains: a structured exploration from a systems perspective. International Journal of Production Management and Engineering 1, 39-54 (2013)

16. Gunasekaran, A., Lai, K.-H., Edwin Cheng, T.: Responsive supply chain: a competitive strategy in a networked economy. Omega 36, 549-564 (2008)

17. Porter, M.E.: Competitive advantage: Creating and sustaining superior performance. Simon and Schuster (2008)

18. http://www. computerdealernews. com/news/microsoft-and-thechannel-by-the-numbers / 17913

19. http://www-01.ibm.com/software/rational/alm/collaborate/

20. http://www.accenture.com/microsites/cloudplatform/Pages/home.aspx

21. Kowalkowski, C.: What does a service-dominant logic really mean for manufacturing firms? CIRP Journal of Manufacturing Science and Technology 3, 285-292 (2010)

22. Bhalla, G.: Collaboration and co-creation: New platforms for marketing and innovation. Springer (2010)

23. Martinez, V., Bastl, M., Kingston, J., Evans, S.: Challenges in transforming manufacturing organisations into product-service providers. Journal of Manufacturing Technology Management 21, 449-469 (2010)

24. Vargo, S.L., Maglio, P.P., Akaka, M.A.: On value and value co-creation: A service systems and service logic perspective. European Management Journal 26, 145-152 (2008) 
25. Payne, A.F., Storbacka, K., Frow, P.: Managing the co-creation of value. Journal of the Academy of Marketing Science 36, 83-96 (2008)

26. Romero, D., Molina, A.: Collaborative networked organisations and customer communities: value co-creation and co-innovation in the networking era. Production Planning \& Control 22, 447-472 (2011)

27. Lusch, R.F., Vargo, S.L., Tanniru, M.: Service, value networks and learning. Journal of the Academy of Marketing Science 38, 19-31 (2010)

28. Ivanov, D., Sokolov, B., Kaeschel, J.: A multi-structural framework for adaptive supply chain planning and operations control with structure dynamics considerations. European Journal of Operational Research 200, 409-420 (2010)

29. Christopher, M.: The agile supply chain: competing in volatile markets. Industrial Marketing Management 29, 37-44 (2000)

30. McCarthy, E.J., Perreault, W.D., Quester, P.G.: Basic marketing: A managerial approach. Irwin Homewood etc. (1990)

31. Conway, T., Swift, J.S.: International relationship marketing-The importance of psychic distance. European Journal of Marketing 34, 1391-1414 (2000)

32. Kaplan, R.S., Norton, D.P.: The strategy-focused organization: How balanced scorecard companies thrive in the new business environment. Harvard Business School Press (2001) 